\title{
Model Uncertainty of Interfacial Area and Mass Transfer Coefficients in Absorption Column Packings
}

\author{
Sumudu S. Karunarathne ${ }^{1}$ Dag A. Eimer ${ }^{2}$ Lars Erik $\varnothing_{i}{ }^{1}$ \\ ${ }^{1}$ Department of Process, Energy and Environmental Technology, University College of Southeast Norway, \\ \{Sumudu.Karunarathne, Lars.Oi\}@usn. no \\ ${ }^{2}$ Tel-Tek, Norway, dag.a.eimeretel-tek.no
}

\begin{abstract}
Uncertainty in model input parameters propagates through the model to make model output imprecision. Here, mathematical models used to calculate interfacial area and mass transfer coefficient for both random and structured packing in a packed bed absorption column was studied to investigate the propagation of model input parameters of viscosity, density and surface tension through the models. Monte Carlo simulation was used to examine the uncertainty propagation, and expectation $\mathrm{E}(\mathrm{Y})$ and standard deviation $\sigma$ for the model output values were determined. This study reveals $\pm 5 \%$ model output uncertainty for mass transfer coefficient and $\pm 3.7 \%$ uncertainty for interfacial area for the Onda, Bravo and Fair models used in random packings. Further, the analysis predicts $\pm 1.3 \%$ of uncertainty for interfacial area and $\pm 0.8 \%$ of uncertainty for mass transfer coefficient for the Rocha's correlations used in structured packings.
\end{abstract}

Keywords: $\quad$ uncertainty, absorption, mass transfer, interfacial area

\section{Introduction}

A mathematical model is a simplified version of a complex phenomenon in which assumptions are made during the model derivation to formulate the relations between parameters through mathematical equations. When input data are not precise, this leads to imprecise output results from the model. It is vital to quantify the uncertainty in model output to acquire an understanding about how accurate the estimated values through models. Generally, uncertainties are described by a probability distribution (Loucks et al, 2005).

Uncertainty of a model output is a result of both uncertain model structure and parameter values (Loucks et al, 2005). In model structure uncertainty, the errors in the model structure compared to the real system, assumptions and numerical approximations in simulation caused to create uncertainty in model output. The uncertain estimates of model parameters also make the model output uncertain. It is difficult to estimate the model structure uncertainty compared to model uncertainty caused by the parameter value. Increase of precision in model parameters can reduce the parameter uncertainty but it does not mean that predictions are accurate.
The analysis of model uncertainty is useful in many scientific applications. Krewski et al, (1995) performed an uncertainty analysis on physiological models using Monte Carlo Simulation. In this study, most of the model parameters were assumed to have a nature of the doubly truncated normal distribution. Spek et al, (2016) discussed improving uncertainty evaluation of process models in $\mathrm{CO}_{2}$ capture by using pedigree analysis. A study on investigating the effect of process uncertainty on the optimal design of a $\mathrm{CO}_{2}$ capture plant was done by Bahakim and Ricardez-Sandoval, (2014). The intention was to find the most economically feasible design for process equipment and acquire optimal operating conditions under uncertain conditions. Mathias and Gilmartin, (2014) evaluated the effect of uncertainty in property models on the simulated performance of solvent-based $\mathrm{CO}_{2}$ capture process.

Gas absorption is a frequently used unit operation in gas treating processes. Packed bed absorption columns are made of either random or structured packing materials. The mass transfer coefficient and the interfacial area are the most important parameters involved with efficiency of packing materials. There have been many attempts to make mathematical models to evaluate both mass transfer coefficient and interfacial area for the both packing materials. Physical properties of viscosity, density and surface tension have an influence on the mass transfer coefficient. Uncertainties of those physical properties propagate through the mass transfer and interfacial area models to make the uncertain model output.

In this study, model uncertainty $\mathrm{U}(Y / X)$ analysis was performed to investigate the input uncertainty propagation of a selected amine through the mass transfer and interfacial area models of the packed bed. The mass transfer coefficient and interfacial area of random packings are calculated by Onda, Bravo and Fair's models (Onda et al, 1967, Bravo and Fair, 1982). Rocha's correlations are used to calculate the mass transfer coefficient of structured packings including sheet metal packing (Rocha et al, 1996). The uncertainties related to measurements and predictions of physical properties were considered as the input uncertainties in Gaussian probability distributions. 


\section{Theory}

In the field of gas treating, various mathematical models are available to calculate desired physical properties in the absorption process. Calculation of gas and liquid side mass transfer coefficients and interfacial area of packed beds have been highly concerned in many research works. Several mathematical models were built to approximate those properties using physical properties of an absorbent such as density, viscosity and surface tension. Most of the available models are based on either two-film theory or penetration theory with some reasonable assumptions (Wang et al, 2005).

The model developed by Onda, Bravo and Fair (Onda et al, 1967, Wang et al, 2005) is widely used to determine the gas and liquid side mass transfer coefficients of random packings. The model is given as,

For the gas side mass transfer coefficient,

$k_{G}=c\left(\frac{D_{G}}{a_{p} d_{p}^{2}}\right)\left(\frac{\rho_{G} u_{G}}{a_{p} \mu_{G}}\right)^{0.7} S c_{G}^{1 / 3}$

For the liquid side,

$k_{L}=\frac{0.0051}{\left(a_{p} d_{p}\right)^{-0.4}}\left(\frac{\mu_{L} g}{\rho_{L}}\right)^{1 / 3}\left(\frac{\rho_{L} u_{L}}{a_{e} \mu_{L}}\right)^{2 / 3} S c_{L}^{-0.5}$

The interfacial area can be determined by,

$\frac{a_{e}}{a_{p}}=1-\exp \left[-1.45\left(\frac{\sigma_{c}}{\sigma_{L}}\right)^{0.75} \operatorname{Re}_{L}^{0.1} \mathrm{Fr}_{L}^{-0.05} \mathrm{We}_{L}^{0.2}\right]$

For this study, Rocha's correlations were considered for structured packing (Rocha et al, 1996).

$k_{G}=0.054 \frac{D_{G}}{s}\left[\frac{\rho_{G} s\left(u_{L e}+u_{G e}\right)}{\mu_{G}}\right]^{0.8} S c_{G}^{0.33}$

$k_{L}=2 \sqrt{\frac{0.9 D_{L} u_{L e}}{\pi s}}$

Where $u_{G e}=\frac{u_{G}}{\varepsilon\left(1-h_{L}\right) \sin \alpha}$

And $\quad u_{L e}=\frac{u_{L}}{\varepsilon h_{L} \sin \alpha}$

The interfacial area is determined by

$\frac{a_{e}}{a_{p}}=F_{S E} \frac{29.12\left(W e_{L} F r_{L}\right)^{0.15} S^{0.359}}{\operatorname{Re}_{L}^{0.2} \varepsilon^{0.6}(1-0.93 \cos (\theta))(\sin (\alpha))^{0.3}}$
For the models mentioned, physical properties of density, viscosity and surface tension in amines were considered as input parameters and the uncertainty associated with these parameters were taken into account for the examination of model uncertainty. This analysis mainly focuses on the evaluation of parameter uncertainty of the models and uncertainty due to models structure will not be discussed here.

Physical properties can be determined by laboratory experiments. In addition to that, it can be determined by models, created using experimental data. Both approaches deal with some level of uncertainty. Eventually, the physical properties are needed to be presented with an uncertainty to get an idea about the level of accuracy. Table 1 lists some measurement uncertainty of viscosity, density and surface tension of different amines.

Guide to the expression of uncertainty in measurement (GUM) (JCGM, 2011) discussed the way of distributions propagate in mutually independent inputs through a model. Figure 1 illustrates the concept of propagation of distribution through a model. The assigned probability distribution function (PDF) for the inputs are represented as $g_{X_{i}}\left(\xi_{i}\right)$ and model output $Y$ is characterized by joint PDF $g_{Y}(\eta)$.

During the model validation, the physical properties predictions are compared with the measured values to observe the model predictability. It gives information about deviation between model predictions and actual values. This also can be considered as a model uncertainty and it contains many uncertainty sources. Onda's correlations for liquid-phase mass transfer fulfill $\pm 20 \%$ of agreement with the large amount of data on organic liquids and water (Potnis and Lenz, 1996).

Table 1. Measurement Uncertainty of physical properties

\begin{tabular}{|l|l|}
\hline Property & \multicolumn{1}{|c|}{ Uncertainty } \\
\hline Viscosity & $\begin{array}{l} \pm 0.015 \mathrm{mPa} \cdot \mathrm{s} \text { (95\% confident level, } \\
\mathrm{k}=2) \text { (Arachchige } \text { et al, 2013) }\end{array}$ \\
\cline { 2 - 2 } & $\begin{array}{l} \pm 0.12 \mathrm{mPa} \cdot \mathrm{s} \text { (95\% confident level, } \\
\mathrm{k}=2) \text { (Sobrino } \text { et al, 2016) }\end{array}$ \\
\hline \multirow{5}{*}{ Density } & $\begin{array}{l} \pm 4.42 \mathrm{~kg} / \mathrm{m}^{3} \text { ( 95\% confident level, } \\
\mathrm{k}=2)\left(\mathrm{CO}_{2} \text { loaded solution) (Jayarathna }\right. \\
\text { et al, 2013) }\end{array}$ \\
\cline { 2 - 2 } & $\begin{array}{l} \pm 0.05 \mathrm{~kg} / \mathrm{m}^{3} \text { (Standard uncertainty) } \\
(\mathrm{CO} 2 \text { loaded solution) (Amundsen } \text { et } \\
\text { Surface }\end{array}$ \\
\hline \multirow{3}{*}{ tension } & $\begin{array}{l} \pm 0.02 \mathrm{mN} / \mathrm{m} \text { (accuracy) (Vazquez } \text { et } \\
\text { al, 1997) }\end{array}$ \\
\cline { 2 - 2 } & $\begin{array}{l} \pm 1.2 \mathrm{mN} / \mathrm{m} \text { ( 95\% confident level, } \\
\mathrm{k}=2)(\mathrm{Jayarathna} \text { et al, } 2013)\end{array}$ \\
\hline
\end{tabular}




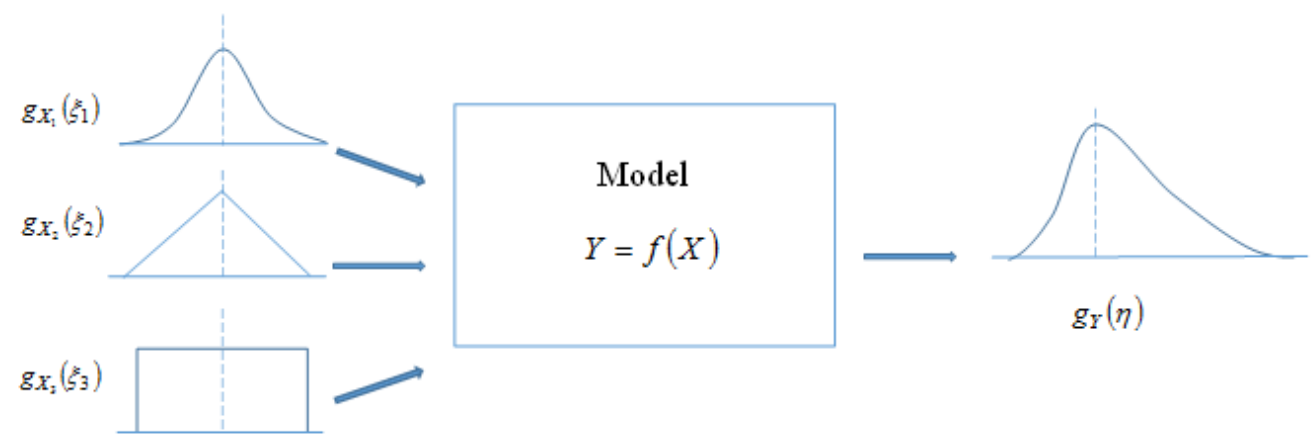

Figure 1. Illustration of the propagation of distribution (JCGM, 2011)

Nookuea et al, (2016) summarized possible uncertainty ranges for different properties of gas and liquid $\mathrm{CO}_{2}$ mixtures and a sensitivity analysis was done considering $\pm 20 \%$ deviation of physical properties to investigate their impact on the design of an absorber.

The standard uncertainty in $Y$ due to uncertainty in $X$

$U(Y)=\sqrt{\operatorname{Var}(Y)}$

$R U(Y)=\frac{\sqrt{\operatorname{Var}(Y)}}{E(Y)} \times 100 \%$

The standard uncertainty in $Y$ due to uncertainty in $X_{j}$ is $U\left(Y \backslash X_{j}\right)$

Then the relative uncertainty is defined as

$$
R U\left(Y \backslash X_{j}\right)=\frac{U\left(Y \backslash X_{j}\right)}{E(Y)} \times 100 \%
$$

\section{Methodology}

In this study, $\mathrm{CO}_{2}$ absorption into $30 \%$ (by weight) monoethanol amine was considered as the physical process. It was assumed that the uncertainty of the physical properties has a Gaussian distribution. Experimentally measured values of viscosity, density and surface tension of monoethanol amine with standard uncertainty $\pm 5 \%$ at $313.15 \mathrm{~K}$ were considered as model input parameters and Monte Carlo techniques were used to estimate uncertainty for the liquid side mass transfer coefficient and interfacial area of the packing materials. Simulations were performed in MATLAB environment and a built-in random number generator was used to generate values from Gaussian distribution for the input properties within the considered uncertainty levels. Table 2 shows the values for the considered inputs with uncertainties.

For the random packings, Ceramic Raschig Rings $(25 \mathrm{~mm})$ and for the structured packings, Sulzer BX
(Gauze) packing were selected for this study. The diffusion coefficients of $\mathrm{CO}_{2}\left(\mathrm{~m}^{2} / \mathrm{s}\right)$ in gas and liquid are $1.70 \times 10^{-5}$ and $2.82 \times 10^{-9}$ respectively (Eimer, 2014). The gas and liquid flow rates were assumed as $1.7 \mathrm{~kg} / \mathrm{m}^{2} \cdot \mathrm{s}$ and $1.85 \mathrm{~kg} / \mathrm{m}^{2} \cdot \mathrm{s}$.

Table 2. Input parameter values and uncertainties

\begin{tabular}{|l|l|l|}
\hline Parameter & Value & Uncertainty \\
\hline Viscosity & $1.628 \mathrm{mPa} \cdot \mathrm{s}$ & $\pm 0.0814 \mathrm{mPa} \cdot \mathrm{s}$ \\
\hline Density & $1003.3 \mathrm{~kg} / \mathrm{m}^{3}$ & $\pm 50.165 \mathrm{~kg} / \mathrm{m}^{3}$ \\
\hline Surface tension & $0.0624 \mathrm{~N} / \mathrm{m}$ & $\pm 0.00312 \mathrm{~N} / \mathrm{m}$ \\
\hline
\end{tabular}

\section{Results}

Initially, all the input parameters were considered together to evaluate uncertainty propagation through the model. The model of interfacial area (Eq (3)) for random packing was considered first and the model output was described using a histogram. Subsequently, the uncertainty predicted for interfacial area was used for the uncertainty evaluation of liquid side mass transfer coefficient from Eq (2). Figure 2 illustrates a histogram of values obtained for the interfacial area of random packing.

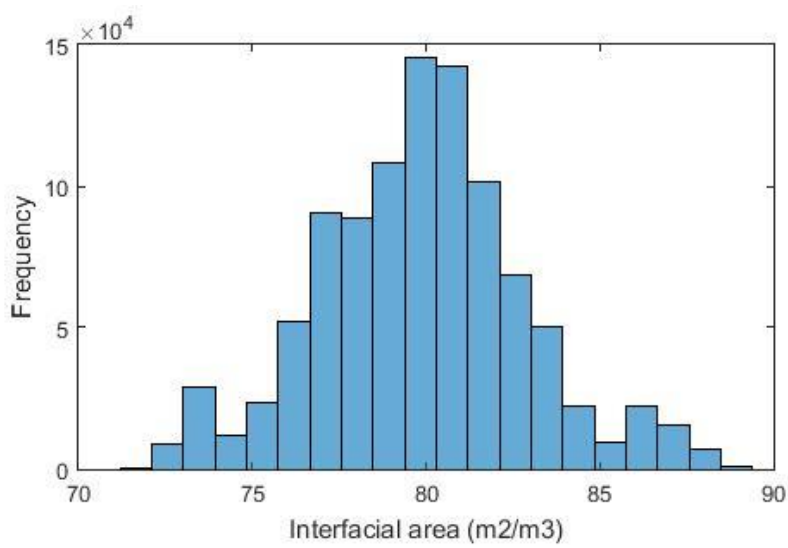

Figure 2. Histogram of interfacial area of random packing

Figure 3 shows the variation occurred for the liquid side mass transfer coefficient under considered input 
uncertainty. Table 3 summarized the calculated expectation and standard deviation for both interfacial area and mass transfer coefficient of Onda, Bravo and Fair's correlations.

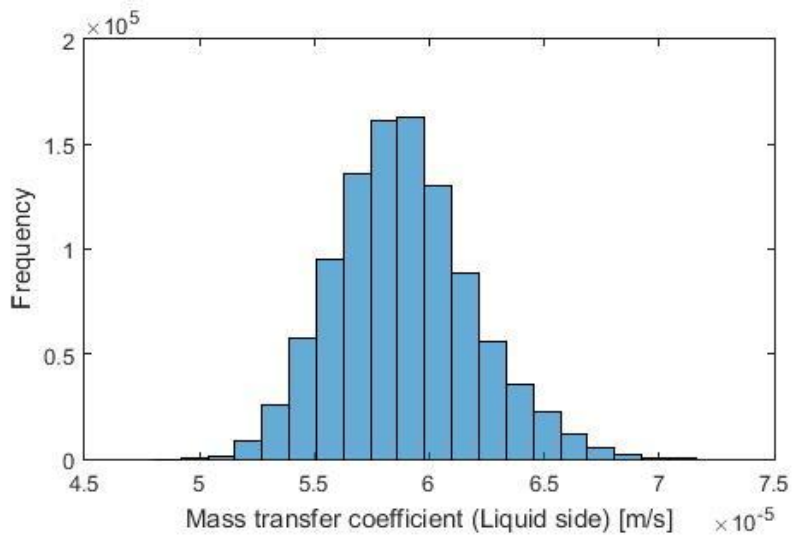

Figure 3. Histogram of mass transfer coefficient (liquid side) of random packing

Table 3. Estimated expectation and standard deviation for the random packings

\begin{tabular}{|l|l|c|}
\hline Model & $\begin{array}{l}\text { Expectation } \\
\text { E(x) }\end{array}$ & $\begin{array}{l}\text { Standard deviation } \\
(\sigma)\end{array}$ \\
\hline $\begin{array}{l}\text { Interfacial } \\
\text { area }\end{array}$ & $79.88 \mathrm{~m}^{2} / \mathrm{m}^{3}$ & $2.97 \mathrm{~m}^{2} / \mathrm{m}^{3}$ \\
\hline $\begin{array}{l}\text { Mass transfer } \\
\text { coefficient }\end{array}$ & $5.9 \times 10^{-5} \mathrm{~m} / \mathrm{s}$ & $2.97 \times 10^{-06} \mathrm{~m} / \mathrm{s}$ \\
\hline
\end{tabular}

Similarly, for the structured packing, Figure 4 shows a histogram created from the values obtained for the interfacial area of structured packing.

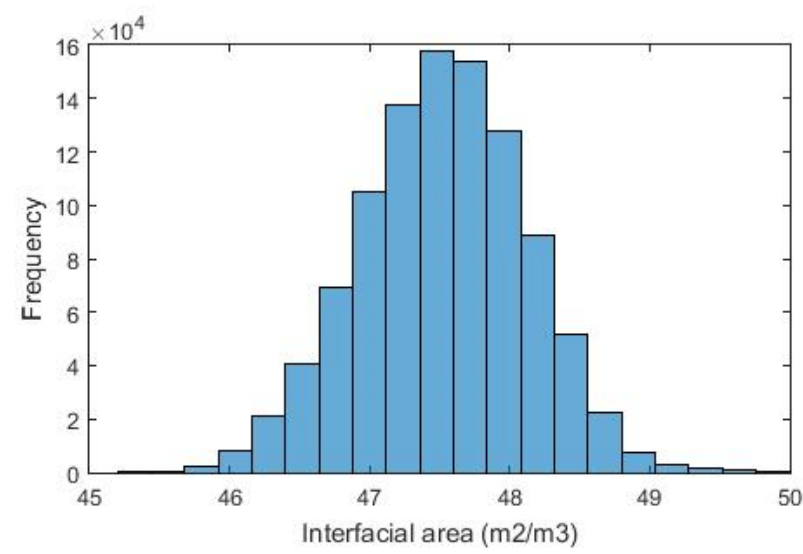

Figure 4. Histogram of interfacial area of structured packing

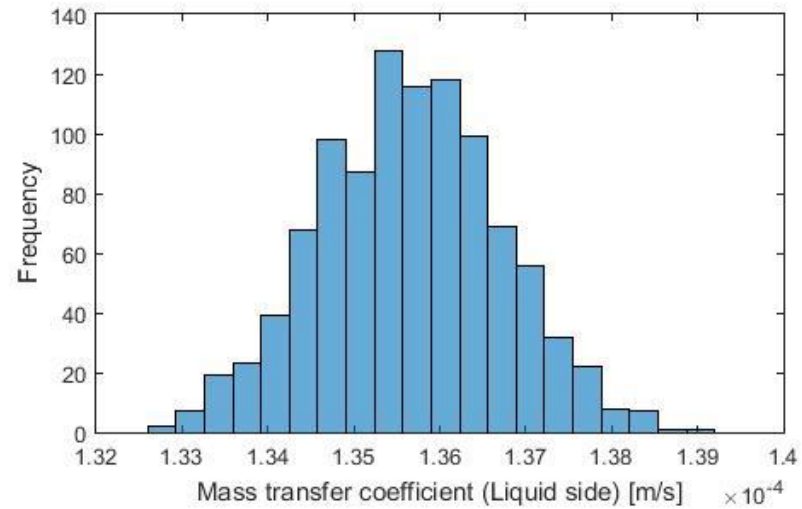

Figure 5. Histogram of mass transfer coefficient (liquid side) of structured packing

Simulation results on mass transfer coefficient (liquid side) of structured packing are shown in Figure 5. Calculated expectation and standard deviation for the interfacial area and mass transfer coefficient of Rocha's correlations under Sulzer BX (Gauze) packing is listed in Table 4.

Table 4. Estimated expectation and standard deviation for the structured packings

\begin{tabular}{|l|l|c|}
\hline Model & $\begin{array}{l}\text { Expectation } \\
\text { E(x) }\end{array}$ & $\begin{array}{l}\text { Standard } \\
\text { deviation }(\sigma)\end{array}$ \\
\hline $\begin{array}{l}\text { Interfacial } \\
\text { area }\end{array}$ & $47.5 \mathrm{~m}^{2} / \mathrm{m}^{3}$ & $0.6 \mathrm{~m}^{2} / \mathrm{m}^{3}$ \\
\hline $\begin{array}{l}\text { Mass transfer } \\
\text { coefficient }\end{array}$ & $1.36 \times 10^{-04} \mathrm{~m} / \mathrm{s}$ & $1.04 \times 10^{-06} \mathrm{~m} / \mathrm{s}$ \\
\hline
\end{tabular}

Results reveal the propagation of uncertainty in model parameters through the mathematical model. This method only addresses the parameter uncertainty and uncertainty due to the model structure is not discussed here.

The relative uncertainty of the parameters uncertainty was evaluated according to the Eq (10). It shows $\pm 3.7 \%$ of uncertainty for interfacial area and $\pm 5 \%$ of uncertainty for mass transfer coefficient for the random packing. Similarly for the structured packings, $\pm 1.3 \%$ of uncertainty for interfacial area and $\pm 0.8 \%$ of uncertainty for mass transfer coefficient.

One advantage of performing this analysis is being able to estimate the relative impacts of input parameter uncertainties. This relative effect of uncertain parameters (viscosity, density and surface tension) were considered individually in uncertainty analysis. Estimated expectations and standard deviations due to the relative parameters in Onda, Bravo and Fair's correlation for random packings are shown in Table 5. 


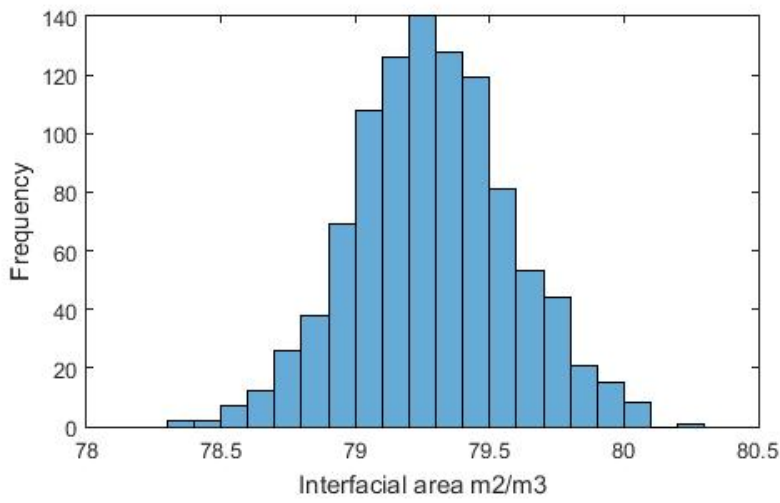

(a)

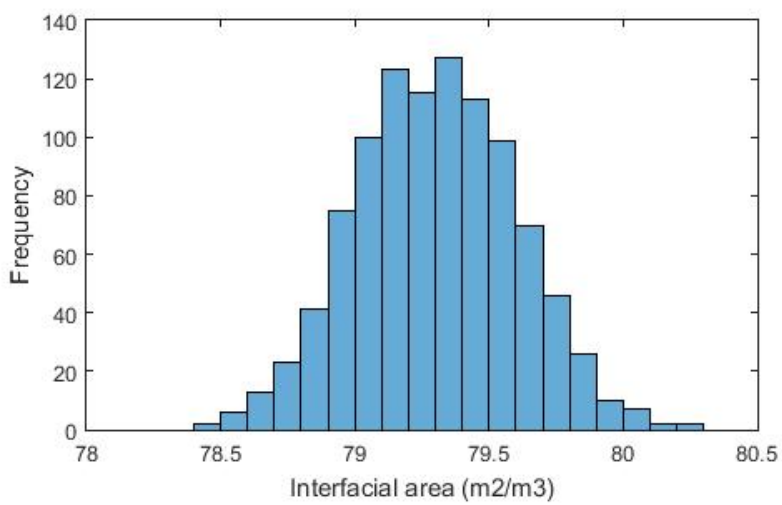

(b)

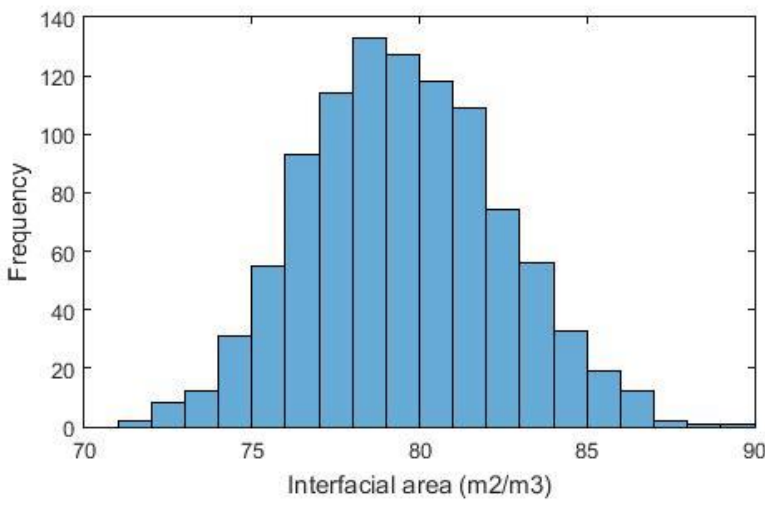

(c)

Figure 6. Histogram of the interfacial area under relative parameter uncertainty. ( $a, b, c$ for interfacial area due to viscosity, density and surface tension respectively)

Table 5. Estimated expectations and standard deviations due to the relative parameters. $a_{e}\left(\mathrm{~m}^{2} / \mathrm{m}^{3}\right), k_{L}(\mathrm{~m} / \mathrm{s})$

\begin{tabular}{|l|l|l|l|l|}
\cline { 3 - 5 } \multicolumn{2}{c|}{} & Viscosity & Density & $\begin{array}{l}\text { Surface } \\
\text { tension }\end{array}$ \\
\hline \multirow{2}{*}{$a_{e}$} & $\mathrm{E}\left(\mathrm{Y} / \mathrm{X}_{\mathrm{j}}\right)$ & 79.3 & 79.3 & 79.5 \\
\cline { 2 - 5 } & $\sigma\left(\mathrm{Y} / \mathrm{X}_{\mathrm{j}}\right)$ & 0.3 & 0.3 & 2.9 \\
\hline \multirow{2}{*}{$k_{L}$} & $\mathrm{E}\left(\mathrm{Y} / \mathrm{X}_{\mathrm{j}}\right)$ & $5.9 \times 10^{-5}$ & $5.9 \times 10^{-5}$ & $5.9 \times 10^{-5}$ \\
\cline { 2 - 5 } & $\sigma\left(\mathrm{Y} / \mathrm{X}_{\mathrm{j}}\right)$ & $2.42 \times 10^{-6}$ & $0.5 \times 10^{-6}$ & $1.36 \times 10^{-6}$ \\
\hline
\end{tabular}

The relative uncertainty $R U\left(Y X_{\mathrm{j}}\right)$ of the effect created by individual model parameters are shown in Table 6 . Uncertainties were estimated for random packings under same input parameter uncertainties as shown in Table 2. The histogram created from model outputs within the study of the effect of individual parameter uncertainty are shown in figure 6 and 7.

Table 6. The relative uncertainty $R U\left(Y X_{\mathrm{j}}\right)$ of the effect created by individual model parameters

\begin{tabular}{|l|c|c|}
\hline \multirow{2}{*}{ Parameter } & \multicolumn{2}{|c|}{ Model } \\
\cline { 2 - 3 } & $\begin{array}{c}\text { Mass transfer } \\
\text { coefficient } k_{L}\end{array}$ & $\begin{array}{c}\text { Interfacial area } \\
a_{e}\end{array}$ \\
\hline Viscosity & $\pm 4.1 \%$ & $\pm 0.38 \%$ \\
\hline Density & $\pm 0.85 \%$ & $\pm 0.38 \%$ \\
\hline Surface tension & $\pm 2.3 \%$ & $\pm 3.65 \%$ \\
\hline
\end{tabular}

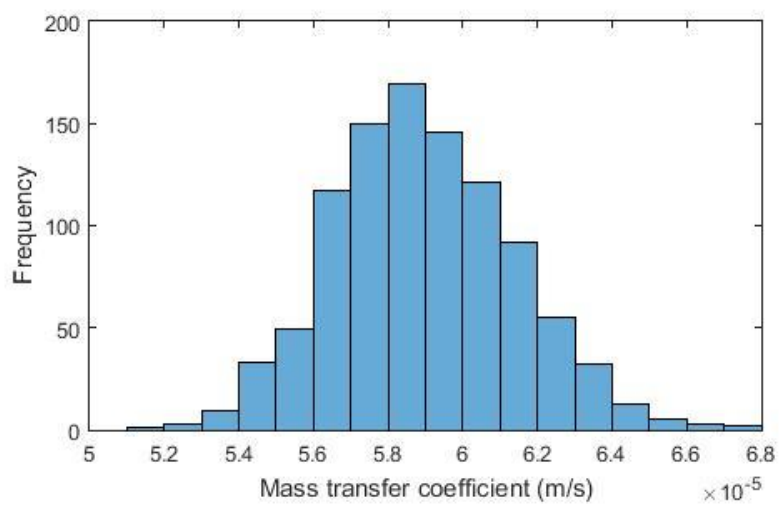

(a)

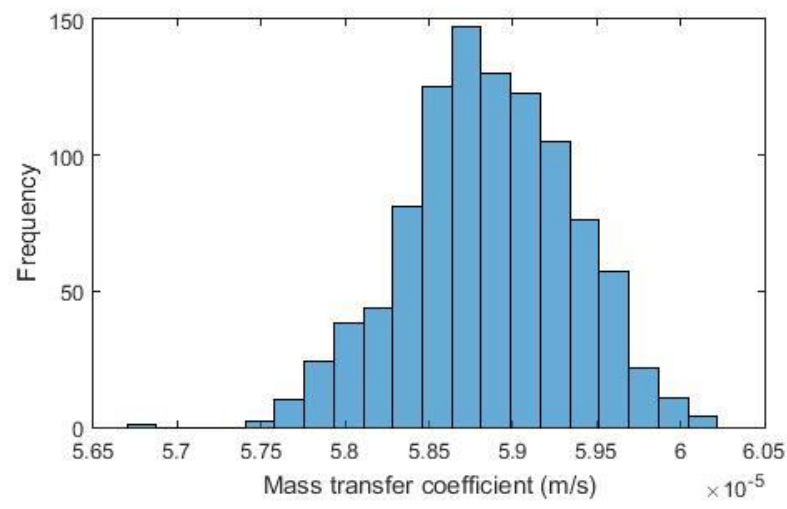

(b)

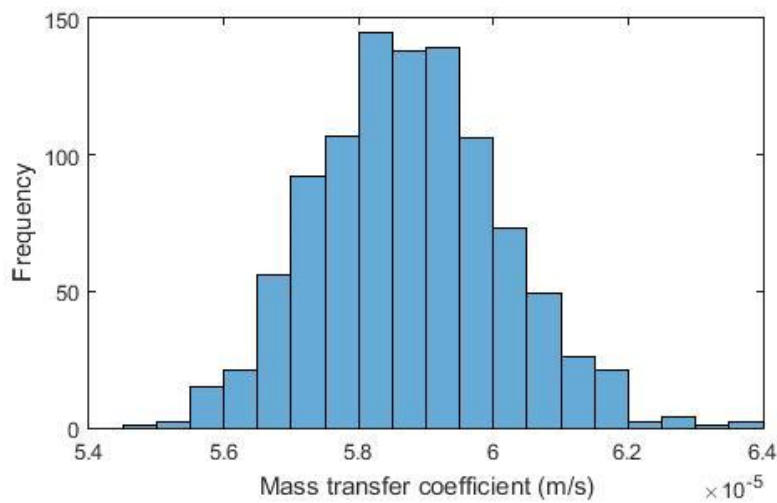

(c)

Figure 7. Histogram of the mass transfer coefficient under relative parameter uncertainty. ( $a, b, c$ for mass transfer coefficient due to viscosity, density and surface tension respectively) 
The effect of individual parameters on parameter uncertainty of the model was compared. Uncertainty of surface tension has a major impact on interfacial area as shown in the results. Viscosity and density have a minor effect in interfacial area. For the mass transfer coefficient, viscosity shows a significant influence in model uncertainty. There, density and surface tension has minor effects.

\section{Conclusion}

Monte Carlo simulation was used to examine uncertainty propagation of model input parameters of viscosity, density and surface tension on the interfacial area and mass transfer coefficients in random and structured packings.

Overall uncertainty of model output gives information about how the model behaves under random behavior of all the input parameters. This study reveals $\pm 5 \%$ model output uncertainty for mass transfer coefficient and $\pm 3.7 \%$ uncertainty for interfacial area for the Onda, Bravo and Fair models used in random packings. Further, the analysis predicts $\pm 1.3 \%$ of uncertainty for interfacial area and $\pm 0.8 \%$ of uncertainty for mass transfer coefficient for the Rocha's correlations used in structured packings.

The relative impact of individual parameters predicts the model sensitivity and individual uncertainty contribution. Uncertainty in surface tension has a significant effect on the uncertainty of interfacial area in random packings that is $\pm 3.65 \%$. According to the considered correlations on random packing, the uncertainty of interfacial area can be reduced by reducing the imprecision of surface tension. Mass transfer coefficient gets a greater influence from viscosity with $\pm 4.1 \%$. Precise input parameter values on viscosity enhance the precision of the mass transfer coefficient.

\section{Nomenclature}

$\begin{array}{ll}a_{e} & \text { Effective specific interfacial area, }\left(\mathrm{m}^{2} / \mathrm{m}^{3}\right) \\ a_{p} & \text { Packing specific surface area, }\left(\mathrm{m}^{2} / \mathrm{m}^{3}\right) \\ c & \text { Packing-specific constant } \\ D & \text { Diffusion constant, } \mathrm{m}^{2} / \mathrm{s} \\ d_{p} & \text { Particle diameter, } \mathrm{m} \\ F_{S E} & \text { Packing surface enhancement factor } \\ F r & \text { Froude number } \\ g & \text { Gravitational acceleration, } \mathrm{m} / \mathrm{s}^{2} \\ h_{L} & \text { Liquid holdup } \mathrm{m}^{3} / \mathrm{m}^{3} \\ k & \text { Mass transfer coefficient, } \mathrm{m} / \mathrm{s} \\ s & \text { Corrugation side length, } \mathrm{m} \\ S c & \text { Schmidt number } \\ u & \text { Superficial velocity, } \mathrm{m} / \mathrm{s} \\ W e & \text { Weber number }\end{array}$

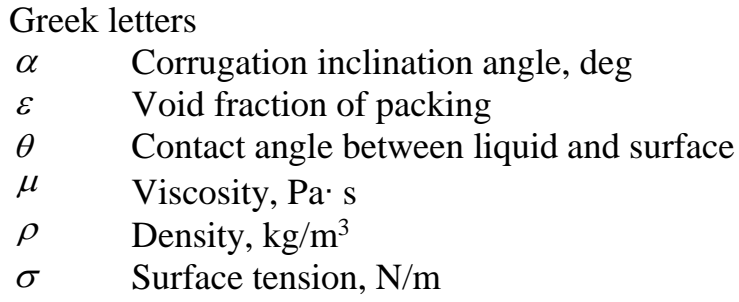

$\begin{array}{ll}\text { Subscripts } \\ G & \text { Gas } \\ L & \text { Liquid } \\ e & \text { Effective } \\ c & \text { Critical }\end{array}$

\section{References}

D. Krewski, Y. Wang, S. Bartlett and K. Krishnan. Uncertainty,variability, and sensitivity analysis in physiological pharmacokinetic models. Journal of Biopharmaceutical Statistics, 5: 245-271, 1995.

D. P. Loucks, E. V. Beek, J. R. Stedinger, J. P. M. Dijkman and M. T. Villars. Water resources systems planning and management: An introduction to methods, models and applications. UNESCO, 2005.

D. Eimer. Gas Treating John Wiley \& Sons, Ltd, 2014.

G. Vazquez, E. Alvarez, J. Navaza, R. Rendo and E. Romero. Surface tension of binary mixtures of water + monoethanolamine and water + 2-amino-2-methyl-1propanol and tertiary mixtures of these amines with water from $25^{\circ} \mathrm{c}$ to $50^{\circ} \mathrm{C}$. Journal of Chemical \& Engineering Data, 42: 57-59, 1997.

G. Wang, X. Yuan and K. Yu. Review of mass-transfer correlation for packed column. Ind.Eng.Chem.Res, 44: 87158729, 2005.

J. A. Rocha, J. Bravo and J. Fair. Distillation Columns Containing Structured Packings: A comprehensive model for their performance. 2. mass-transfer model. Americal Chemical Society, 1660-1667, 1996.

JCGM. Evaluation of measurement data - supplement 2 to the "guide to the expression of uncertainty in measurement" extension to any number of output quantities. JCGM 102:2011.

J. L. Bravo and J. R. Fair. Generalized correlation for mass transfer in packed distillation columns. Ind. Eng. Chem. Process Des. Dev, 21: 162-170, 1982.

K. Onda, E. Sada and H. Takeuchi. Gas absorption with chemical reaction in packed columns. Journal of Chemical Engineering of Japan, 62-66, 1967.

M. Spek, A. Ramirez and A. Faaij. Improving uncertainty evaluation of process models by using pedigree analysis. a 
case study on $\mathrm{CO}_{2}$ capture with monoethanolamine. Computers and Chemical Engineering, 85: 1-15, 2016.

M. Sobrino, E. Concepcion, A. Hernandez and M. Martin. Viscosity and density measurements of aqueous amines at high pressures: mdea-water and mea-water mixtures for $\mathrm{co}_{2}$ capture. J.Chem.Thermodynamics, 98, 231-241, 2016.

P. Mathias and J. Gilmartin. Quantitative evaluation of the effect of uncertainty in property models on the simulated performance of solvent-based $\mathrm{CO}_{2}$ capture. Energy Procedia : GHGT-12, 63: 1171-1185, 2014.

S. Bahakim and L. Ricardez-Sandoval. Optimul steady-state design of a post-combustion $\mathrm{CO}_{2}$ capture plant under uncertainty. Energy Procedia, 63: 1608-1616, 2014.

S. Jayarathna, A. Weerasooriya, S. Dayarathna, D. Eimer and M. Melaaen. Densities and surface tensions of $\mathrm{Co}_{2}$ loaded aqueous monoethanolamine solutions with $\mathrm{r}=(0.2$ to 0.7$)$ at $\mathrm{t}=(303.15$ to 333.15$) \mathrm{k}$. Journal of Chemical \& Engineering Data, 58: 986-992, 2013.

S. Potnis and T. lenz. Dimensionless mass-transfer correlations for packed-bed liquid desiccant contactors. Americal Chemical Society, 4185-4193, 1996.

T. Amundsen, L. Øi and D. Eimer. Density and viscosity of monoethanolamine+water+carbon dioxide from $(25 \text { to } 80)^{0} \mathrm{c}$ Journal of Chemical \& Engineering Data, 54: 3096-3100, 2009.

U. Arachchige, N. Aryal, D. Eimer and M. Melaaen. Viscosities of pure and aqueous solutions of monoethanolamine (mea), diethanolamine (dea) and nmethyldiethanolamine (mdea). Annual Transaction of the Nordic Rheology Society, 21: 299-306, 2013.

W. Nookuea, Y. Tan, H. Li, E. Thorin and J. Yan. Impact of thermo-physical properties of gas and liquid phases on design of absorber for $\mathrm{CO}_{2}$ capture using monoethanolamine. International Journal of Greenhouse Gas Control, 52: 190200, 2016. 